\title{
Application of Teaching Learning Based Optimization in antenna designing
}

\author{
Surabhi Dwivedi ${ }^{1 *}$, Vivekanand Mishra ${ }^{1}$, Yogesh Kosta ${ }^{2}$, \\ ${ }^{1}$ Sardar Vallabhbhai National Institute Of Technology, Surat, Gujarat, India \\ ${ }^{2}$ Marwadi Education Foundations Group of Institutions,Rajkot, Gujarat \\ *corresponding author, E-mail: sur_2310@yahoo.co. in
}

\begin{abstract}
Numerous optimization techniques are studied and applied on antenna designs to optimize various performance parameters. Authors used many Multiple Attributes Decision Making(MADM) methods, which include, Weighted Sum Method (WSM), Weighted Product Method (WPM), Technique for Order Preference by Similarity to Ideal Solution (TOPSIS), Analytic Hierarchy Process (AHP), ELECTRE, etc. Of these many MADM methods, TOPSIS and AHP are more widely used decision making methods. Both TOPSIS and AHP are logical decision making approaches and deal with the problem of choosing an alternative from a set of alternatives which are characterized in terms of some attributes. Analytic Hierarchy Process (AHP) is explained in detail and compared with WSM and WPM. Authors finally used Teaching-Learning-Based Optimization (TLBO) technique; which is a novel method for constrained antenna design optimization problems.
\end{abstract}

\section{Introduction}

Multiple Criterion Decision Making (MCDM) refers to making decisions from multiple conflicting criteria. MCDM is broadly classified into two categories: multiple attribute decision making (MADM) and multiple objective decision making (MODM). The choice of selecting the best method depends on whether the problem is a selection problem or a design problem. MODM methods have decision variable values with a large number of choices and select the best that should satisfy the decision maker's constraints and preference priorities. Teaching Learning Based Optimization(TLBO) method is a kind of MODM technique. MADM methods, on the other hand, are generally discrete, with a limited number of predetermined alternatives. MADM is an approach employed to solve problems involving selection from among a finite number of alternatives. A MADM method specifies how attribute information is to be processed in order to arrive at the best choice. MADM methods require both inter- and intra-attribute comparisons, and involve appropriate explicit tradeoffs[1].

Each decision table (or decision matrix) in MADM methods has four main parts, namely: (a) alternatives, (b) attributes, (c) weight, and (d) measures of performance of alternatives w.r.t. the attributes. The decision table is shown in Table 1. The decision table shows alternatives, $A_{i}$ (for $\mathrm{i}$
$=1,2, . ., \mathrm{N})$, attributes, $B_{j}$ (for $\left.\mathrm{j}=1,2, . ., \mathrm{M}\right)$, weights of attributes, $w_{j}$ (for $\mathrm{j}=1,2, . ., \mathrm{M}$ ) and the measures of performance of alternatives, $m_{i j}($ for $\mathrm{i}=1,2, . ., \mathrm{N} ; \mathrm{j}=1,2, . ., \mathrm{M}$ ) [1].

\section{MADM Methods}

Following are the different types of MADM methods used by the present team of authors for their specific application of antenna designing.

\subsection{Simple Additive Weighting (SAW) Method}

This is also called the Weighted Sum Method (Fishburn, 1967) and is the simplest and widest used MADM method. Each attribute is given a weight and the sum of all weights must be 1 . The overall or composite performance score of an alternative is given by Equation 1 .

$$
P_{i}=\sum_{j=1}^{M} w_{j} m_{i j}
$$

A beneficial attribute (e.g. Peak Gain(PG), Directivity(D), Radiation Efficiency(RE), Front to Back Ratio(FBR)) means its higher values are desirable for the given decision-making problem. By contrast, nonbeneficial attribute (e.g. Return Loss(RL), Voltage Standing Wave Ratio(VSWR), Loss Tangent(LT)) is that for which the lower values are desirable.

$$
P_{i}=\left[\sum_{j=1}^{M} w_{j}\left(m_{i j}\right)_{n o r m a l}\right] / \sum_{j=1}^{M} w_{j}
$$

\subsection{Weighted Product Method (WPM)}

This method is similar to SAW. The main difference is that, instead of addition in the model, there is multiplication (Miller and Starr, 1969). The overall or composite performance score of an alternative is given by Equation 3 .

$$
P_{i}=\prod_{j=1}^{M}\left[\left(m_{i j}\right)_{n o r m a l}\right]^{w_{j}}
$$

\subsection{Analytic Hierarchy Process (AHP) Method}

One of the most popular analytical techniques for complex decision-making problems is the analytic hierarchy process 
(AHP). In 1980, Saaty developed AHP, which decomposes a decision-making problem into a system of hierarchies of objectives, attributes and alternatives.

An AHP hierarchy can have as many levels as needed to fully characterize a particular decision situation of designing. A number of functional characteristics make AHP a useful methodology. These include the ability to handle decision situations involving subjective judgments, multiple decision makers, and the ability to provide measures of consistency of preference [2]. AHP can efficiently deal with tangible (i.e., objective) as well as non-tangible (i.e., subjective) attributes, especially where the subjective judgments of different individuals are required[1].

\subsection{Comparison of SAW, WPM and AHP}

Table 2 is drawn for selecting materials for substrate: where, DC: Dielectric Constant, LT: Loss Tangent, RF: Radio Frequency, RL: Return Loss, VSWR: Voltage Standing Wave Ratio, PG: Peak Gain, D: Directivity, RE: Radiation Efficiency, FBR: Front to Back Ratio.

All the steps of AHP method are explained in detail in below mentioned Tables 3, Table 4 and Table 5 .

In the Table 6 below, hierarchy generation using all the three methods is shown.

\section{Teaching Learning Based Optimization in Antenna Designing}

Teaching-Learning-Based Optimization algorithm (TLBO) is a teaching-learning process inspired algorithm proposed by Rao et al. [3] which is based on the effect of influence of a teacher on the result of learners in a class. The algorithm replicates the teaching-learning ability of teacher and learners in a class room. Teacher and learners are the two important components of the algorithm and describes two basic modes of the learning, through teacher (known as teacher phase) and interacting with the other learners (known as learner phase). The output in TLBO algorithm is considered in terms of grades of the learners which depend on the quality of teacher. In the entire population the best solution is considered as the teacher[4].

The working of TLBO is divided into two parts, Teacher phase and Learner phase.

i) Teacher phase

It is first part of the algorithm where learners learn through the teacher [3].

\section{ii) Learner phase}

It is second part of the algorithm where learners increase their knowledge by interaction among themselves. A learner interacts randomly with other learners for enhancing his or her knowledge[4].

The implementation steps of the TLBO are summarized below:

Step 1: Initialize the population (i.e. learners) and design variables of the optimization problem (i.e number of subjects offered to the learner) with random generation and evaluate them. In the case of antenna designing, different subjects are anonymous to the performance parameters DC, LT, RF, RL, VSWR, PG, D, RE and FBR)

Step 2: Select the best learner of each subject as a teacher for that subject and calculate mean result of learners in each subject.Different learners in this case are different dielectric materials chosen as antenna substrate; Bakelite, Diamond, RT Duroid 5880, FR4 epoxy, Rogers RT/ duroid 6006, Teflon.

Step 3: Evaluate the difference between current mean result and best mean result by utilizing the teaching factor (TF) which is taken as 1.

Step 4: Update the learners knowledge with the help of teachers knowledge.

Step 5: Update the learners knowledge by utilizing the knowledge of some other learner.

Step 6: Repeat the procedure from step 2 to 5 till the termination criterion is met.

\section{Design and simulation}

. The negative parameters are extracted by placing the unit cell of metamaterial design within the waveguide as shown in fig 1 . The retrieval method used in this paper is based on the approach used by Xudong Chen et. al. in [5]. The negative values of impedance(refer fig 2), refractive index(refer fig 3), permittivity(refer fig 4) and permeability (refer fig 5) are plotted using matlab coding of Drude model.

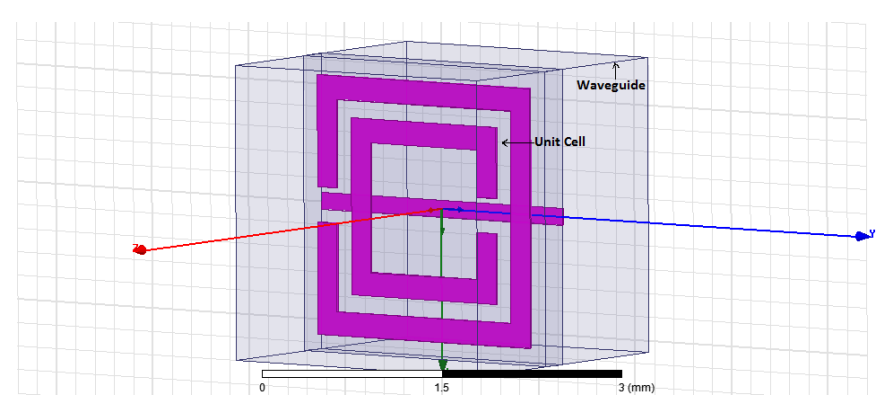

Figure 1: Unit cell in waveguide

Extracted negative parameters are shown in the figures drawn below:

Hence, it is proved that the unit cell behaves as MTM under desired band of frequency region. Then array of unit cells are placed over a patch to improve its directivity as shown in fig 6 and the spacing height is optimized using the above mentioned optimization techniques. The dielectric constant of the substrate is chosen by using TLBO algorithm as stated in section 3 . 


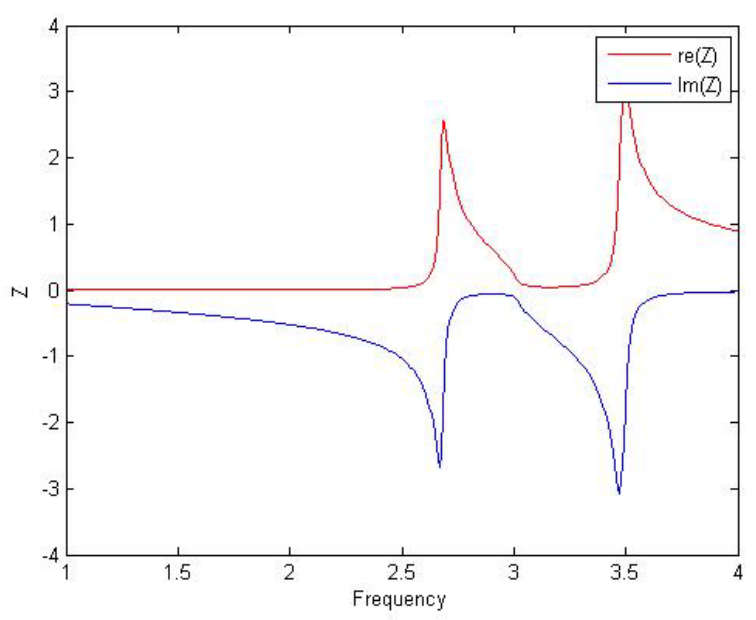

Figure 2: Impedance of unit cell

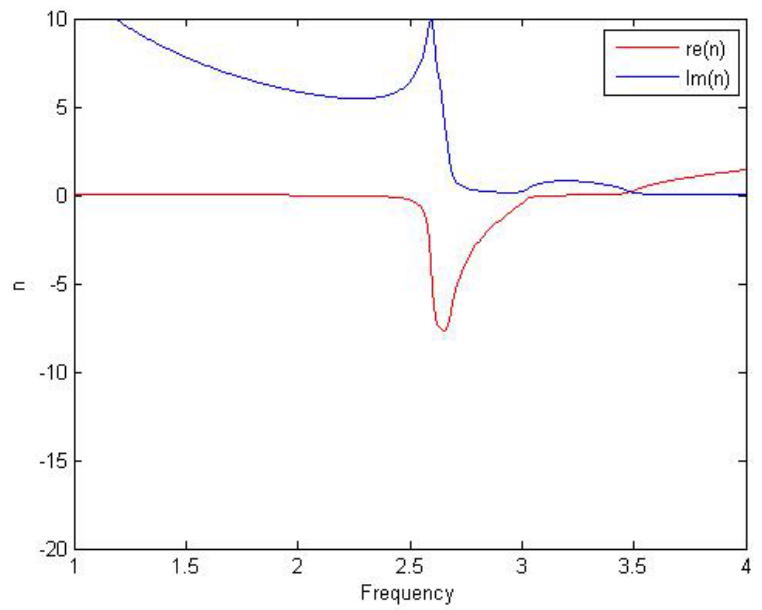

Figure 3: Refractive Index of Unit Cell

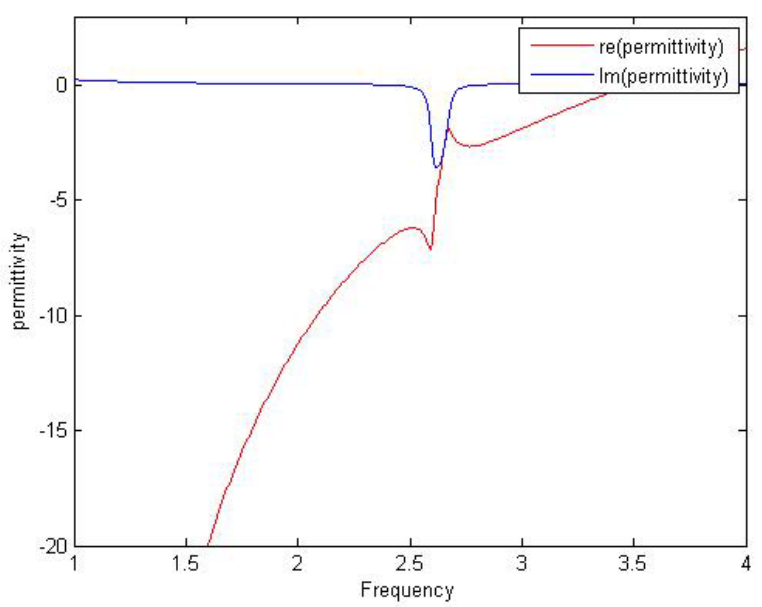

Figure 4: Permittivity of unit cell

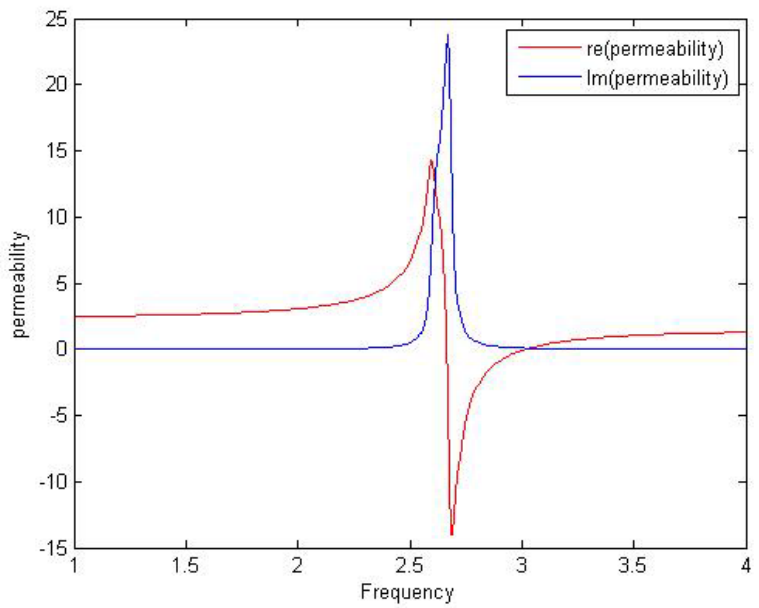

Figure 5: Permeability of unit cell

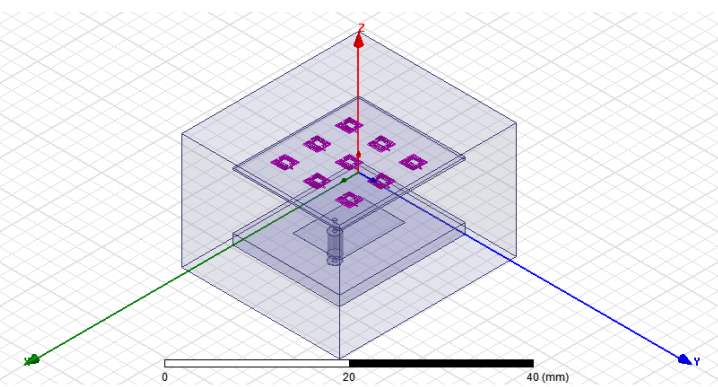

Figure 6: Patch cover 


\section{Applications of radome structure}

As the LHM have negative refractive index it can be used to realize a focusing flat lens [6], whereas positive refractive index materials always require curved surfaces to focus EM waves [7].

Negative refraction by a slab of material bends a ray of light back toward the axis and thus has a focusing effect at the point where the refracted rays meet the axis as shown in fig 7. It was recently observed that a negative index lens exhibits an entirely new type of focusing phenomenon, bringing together not just the propagating rays but also the finer details of the electromagnetic near fields that are evanescent and do not propagate [8] as shown in fig 8 .

\section{Conclusion}

The extracted result parameters obtained by using optimization algorithms are shown to be in excellent agreement with simulation results. It is concluded that numerous optimization techniques can be considered for antenna designing. And the selection of the best optimization method depends upon the designer's perspectives and his requirements. Proposed miniaturized structures is used to characterize and improve the directivity of microstrip patch antenna for the required frequency of operation of 1 to $4 \mathrm{GHz}$. Comparative result analysis is obtained for three different types of optimization techniques. Directivity is improved by optimizing the spacing height at $8.4 \mathrm{~mm}$. The designed antenna is very useful for triband operation for several wireless applications in $\mathrm{L}$ and $\mathrm{S}$ band communication. They possess inherent advantages like reduced sizes. Ultimately TeachingLearning Based Optimization Technique has been used to enhance the performance parameters of the antenna.The author looks forward to the implementation of TLBO concept for radome structure, which can further improve the present status of microstrip patch antenna performance. The proposed structure has compact size, convenient fabrication procedures and low cost.

\section{Acknowledgement}

The current team of authors would like to thank Dr. Ved

Vyas Dwivedi for his technical guidance.

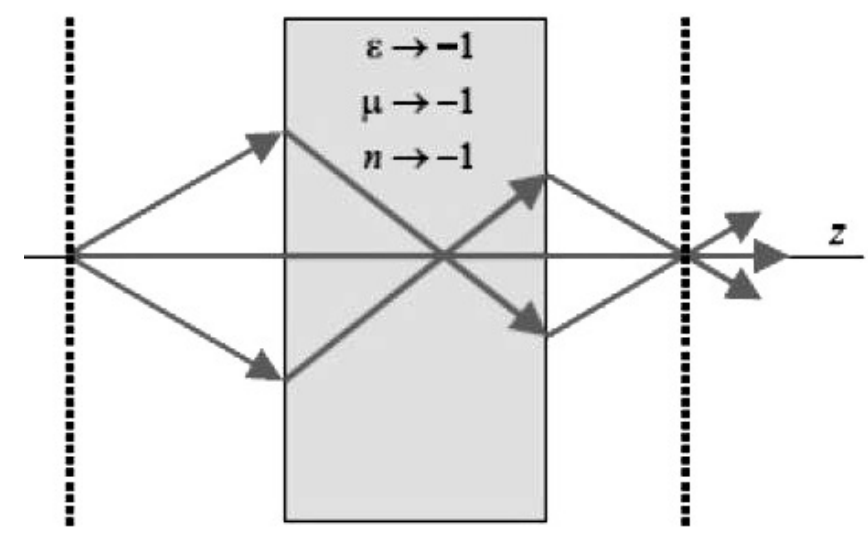

Figure 7: LHM slab as focusing lens [8]

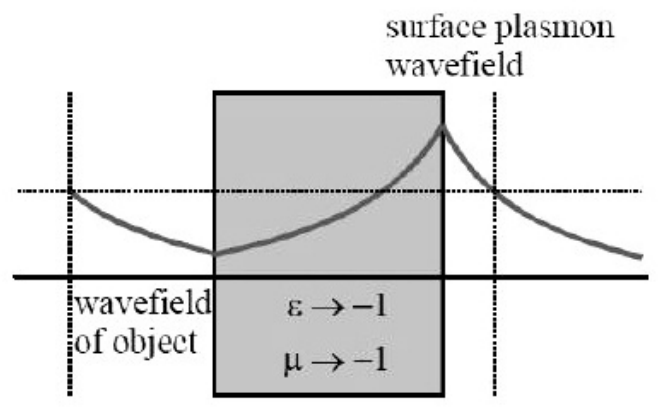

Figure 8: Near-field enhancement using a metamaterial [8] 
Table 1: Decision table in MADM methods

\begin{tabular}{ccccccc} 
Alternatives & \multicolumn{2}{l}{ Attributes } & & & & \\
\hline & B1 & B2 & B3 & -- & -- & BM \\
& (w1) & (w2) & (w3) & $(-)$ & $(-)$ & $(\mathrm{wM})$ \\
\hline $\mathrm{A} 1$ & $\mathrm{~m} 11$ & $\mathrm{~m} 12$ & $\mathrm{~m} 13$ & -- & -- & $\mathrm{m} 1 \mathrm{M}$ \\
$\mathrm{A} 2$ & $\mathrm{~m} 21$ & $\mathrm{~m} 22$ & $\mathrm{~m} 23$ & -- & -- & $\mathrm{m} 2 \mathrm{M}$ \\
$\mathrm{A} 3$ & $\mathrm{~m} 31$ & $\mathrm{~m} 32$ & $\mathrm{~m} 33$ & -- & -- & $\mathrm{m} 3 \mathrm{M}$ \\
---- & -- & -- & -- & -- & -- & -- \\
---- & -- & -- & -- & -- & -- & -- \\
$\mathrm{AN}$ & $\mathrm{mN} 1$ & $\mathrm{mN} 2$ & $\mathrm{mN} 3$ & -- & -- & $\mathrm{mNM}$
\end{tabular}

Table 2: Selection of Substrate Material

\begin{tabular}{lccccccccc} 
Material & DC & LT & $\begin{array}{c}\text { RF } \\
(\mathrm{GHz})\end{array}$ & $\begin{array}{c}\text { RL } \\
(\mathrm{dB})\end{array}$ & VSWR & $\begin{array}{c}\text { PG } \\
(\mathrm{dB})\end{array}$ & $\begin{array}{c}\mathrm{D} \\
(\mathrm{dB})\end{array}$ & $\begin{array}{c}\text { RE } \\
(\%)\end{array}$ & FBR \\
\hline Vacuum & 1 & 0 & 2.44 & -10.1958 & 1.8951 & 4.1967 & 4.2046 & 99.81 & 6.92 \\
Air & 1.0006 & 0 & 2.44 & -9.8920 & 1.9948 & 4.1586 & 4.1553 & 100.08 & 6.82 \\
Bakelite & 4.8 & 0.002 & 2.41 & -7.5913 & 2.4322 & 1.9922 & 2.2439 & 88.78 & 8.2 \\
Diamond & 16.5 & 0 & 2.43 & -3.1708 & 5.5394 & 1.0889 & 1.108 & 98.27 & 2.88 \\
RT Duroid 5880 & 2.2 & 0.0009 & 2.42 & -7.8571 & 2.3890 & 3.3201 & 3.4473 & 96.31 & 14.77 \\
FR4 epoxy & 4.4 & 0.2 & 2.43 & -18.08 & 1.34 & 1.1296 & 2.3311 & 48.45 & 9.55 \\
$\quad$ Rogers RT & 6.15 & 0.0019 & 2.42 & -6.4392 & 2.9276 & 1.7019 & 1.927 & 88.32 & 6.28 \\
/ duroid 6006 & 2.1 & 0.001 & 2.43 & -9.4656 & 2.0134 & 3.3219 & 3.5047 & 94.78 & 15.93 \\
$\quad$ Teflon & & & & & & & & &
\end{tabular}

Table 3: AHP: Step1

\begin{tabular}{lcccccccc} 
Materials & RF & RL & VSWR & PG & D & RE & FBR & Index/Score \\
\hline Bakelite & 0.2608 & 0.0934 & 0.0747 & 0.0472 & 0.0479 & 0.0230 & 0.0006 & 0.5480 \\
Diamond & 0.2208 & 0.0237 & 0.0190 & 0.0245 & 0.0080 & 0.0013 & 0 & 0.2976 \\
RT Duroid 5880 & 0.1351 & 0.0342 & 0.0419 & 0.0255 & 0.0013 & 0 & 0 & 0.2381 \\
FR4 epoxy & 0.0781 & 0.0748 & 0.0255 & 0.0004 & 0 & 0 & 0 & 0.1789 \\
Rogers RT/ duroid 6006 & 0.0745 & 0.0090 & 0.0006 & 0 & 0 & 0 & 0 & 0.0842 \\
Teflon & 0.0253 & 0.0006 & 0 & 0 & 0 & 0 & 0 & 0.0260
\end{tabular}

Table 4: AHP: Step2

\begin{tabular}{lcccccccccc} 
& RF & RL & VSWR & PG & D & RE & FBR & $\begin{array}{c}\text { Geometric } \\
\text { mean }\end{array}$ & weightage & percentage \\
\hline RF & 1 & 3 & 3 & 5 & 5 & 7 & 5 & 2.6272 & 0.2608 & 26.0844 \\
RL & 0.33 & 1 & 3 & 5 & 5 & 7 & 5 & 2.2425 & 0.2226 & 22.2651 \\
VSWR & 0.33 & 0.33 & 1 & 3 & 3 & 5 & 3 & 1.3666 & 0.1356 & 13.5684 \\
PG & 0.2 & 0.2 & 0.33 & 1 & 1 & 5 & 3 & 0.7935 & 0.0787 & 7.87862 \\
D & 0.2 & 0.2 & 0.33 & 1 & 1 & 5 & 3 & 0.7541 & 0.0748 & 7.48738 \\
RE & 0.14 & 0.14 & 0.2 & 0.2 & 0.2 & 1 & 0.33 & 0.2570 & 0.0255 & 2.55238 \\
FBR & 0.2 & 0.2 & 0.33 & 0.33 & 0.33 & 3 & 1 & 0.0133 & 0.0013 & 0.13237
\end{tabular}

Table 5: AHP: Step3

\begin{tabular}{|c|c|c|c|c|c|c|c|c|}
\hline & $\mathrm{RF}$ & RL & VSWR & PG & D & RE & FBR & Index/Score \\
\hline $\mathrm{RF}$ & 0.2608 & 0.6679 & 0.4070 & 0.3939 & 0.3743 & 0.1786 & 0.0066 & 2.2894 \\
\hline RL & 0.0734 & 0.1356 & 0.2363 & 0.3743 & 0.1276 & 0.0092 & 0 & 0.9567 \\
\hline VSWR & 0.0447 & 0.0259 & 0.07487 & 0.0765 & 0.0039 & 0 & 0 & 0.2261 \\
\hline PG & 0.0157 & 0.0149 & 0.0084 & 0.0013 & 0 & 0 & 0 & 0.0404 \\
\hline $\mathrm{D}$ & 0.0149 & 0.0051 & 0.0004 & 0 & 0 & 0 & 0 & 0.0205 \\
\hline $\mathrm{RE}$ & 0.0035 & 0.0001 & 0 & 0 & 0 & 0 & 0 & 0.0037 \\
\hline FBR & 0.0002 & 0 & 0 & 0 & 0 & 0 & 0 & $\begin{array}{l}0.0002 \\
2.2894\end{array}$ \\
\hline
\end{tabular}

Table 6: Comparison of all the three methods of decision making

\begin{tabular}{llllll} 
Materials & AHP & Materials & WPM & Materials & SAW \\
\hline 6 & 0.0260 & 2 & 0.6295 & 6 & 0.0260 \\
5 & 0.0842 & 1 & 0.7038 & 5 & 0.0842 \\
4 & 0.1789 & 3 & 0.8962 & 4 & 0.1789 \\
3 & 0.2381 & 5 & 0.9726 & 3 & 0.2381 \\
2 & 0.2976 & 4 & 0.9979 & 2 & 0.2976 \\
1 & 0.5480 & 6 & 0.9989 & 1 & 0.5480
\end{tabular}




\section{References}

[1] R. V. Rao, Decision Making in Manufacturing Environment Using Graph Theory and Fuzzy Multiple Attribute Decision Making Methods: Volume 2. Springer, 2012, vol. 2.

[2] E. Triantaphyllou, Multi-criteria decision making methods. Springer, 2000.

[3] R. Rao, V. Savsani, and D. Vakharia, "Teachinglearning-based optimization: A novel method for constrained mechanical design optimization problems," Computer-Aided Design, vol. 43, no. 3, pp. 303-315, 2011.

[4] R. V. Rao and V. J. Savsani, Mechanical design optimization using advanced optimization techniques. Springer, 2012.

[5] X. Chen, T. M. Grzegorczyk, B.-I. Wu, J. Pacheco Jr, and J. A. Kong, "Robust method to retrieve the constitutive effective parameters of metamaterials," Physical Review E, vol. 70, no. 1, p. 016608, 2004.

[6] J. B. Pendry, "Negative refraction makes a perfect lens," Physical review letters, vol. 85, no. 18, p. 3966, 2000.

[7] K. Aydin, I. Bulu, and E. Ozbay, "Focusing of electromagnetic waves by a left-handed metamaterial flat lens," Opt. Express, vol. 13, no. 22, pp. 8753-8759, 2005.

[8] D. Smith, J. Pendry, and M. Wiltshire, "Metamaterials and negative refractive index," Science, vol. 305, no. 5685, pp. 788-792, 2004. 